Article

\title{
Synthesis of a Novel Fluorescent Sensor Bearing Dansyl Fluorophores for the Highly Selective Detection of Mercury (II) Ions
}

\author{
Nantanit Wanichacheva ${ }^{1, *}$, Supranee Watpathomsub ${ }^{1}$, Vannajan Sanghiran Lee ${ }^{2}$ and Kate \\ Grudpan $^{2}$
}

1 Department of Chemistry, Faculty of Science, Silpakorn University, Nakorn Pathom 73000, Thailand; E-Mails: watpathomsub.s.j@gmail.com (S.W.)

2 Department of Chemistry and Center for Innovation in Chemistry, Faculty of Science, Chiang Mai University, Chiang Mai 50200, Thailand; E-Mails: vannajan@gmail.com (V.S.L.); kgrudpan@gmail.com (K.G.)

* Author to whom correspondence should be addressed; E-Mail: nantanit@su.ac.th; Tel.: +66-34-255797; Fax: +66-34-271356.

Received: 1 February 2010; in revised form: 22 February 2010 / Accepted: 8 March 2010 / Published: 12 March 2010

\begin{abstract}
A new macromolecule possessing two dansyl moieties and based on 2-[4-(2aminoethylthio)butylthio]ethanamine was prepared as a fluorescent sensor and its mercury sensing properties toward various transition metal, alkali, and alkali earth ions were investigated. The designed compound exhibited pronounced $\mathrm{Hg}^{2+}$-selective ON-OFF type fluorescence switching upon binding. The new compound provided highly selective sensing to $\mathrm{Hg}^{2+}$ in acetonitrile-water solvent mixtures with a detection limit of $2.49 \times 10^{-7}$ $\mathrm{M}$ or $50 \mathrm{ppb}$. The molecular modeling results indicated that ions-recognition of the sensor originated from a self assembly process of the reagent and $\mathrm{Hg}^{2+}$ to form a helical wrapping structure with the favorable electrostatic interactions of $\mathrm{Hg}^{2+}$ coordinated with sulfur, oxygen, nitrogen atoms and aromatic moieties.
\end{abstract}

Keywords: mercury sensor; fluoroionophore; $\mathrm{Hg}^{2+}$-selectivity; fluorescent sensor 


\section{Introduction}

Mercury is a highly toxic and hazardous environmental contaminant, even at low levels [1]. To allow mercury detection with rapid, convenient and inexpensive methods, a fluorescent sensor can be useful. A number of macromolecules have been proposed and prepared as new fluorescent sensors due to their high selectivity and sensitivity for the detection of metal cations, including mercury [2-8]. Recently many fluorescent mercury ionophores have been designed for $\mathrm{Hg}^{2+}$-sensing such as calixarene [9], hydroxyquinolines [10-11], azines [12], cyclams [13-15], diazacrown ethers [16] dioxocyclams [17], diazatetrathia crown ethers [18], and most of these studies have shown that nitrogen, oxygen and sulfur atoms present in the ionophores can promote the coordination of $\mathrm{Hg}^{2+}$ [10-18]. However, some of these sensors have drawbacks in term of synthetic difficulty, high cost of starting materials or lack of selectivity.

Although many fluorescent mercury sensors have been designed for $\mathrm{Hg}^{2+}$-sensing, they often suffered from some interference by foreign ions, particularly silver $\left(\mathrm{Ag}^{+}\right)$, copper $\left(\mathrm{Cu}^{2+}\right)$ and cadmium $\left(\mathrm{Cd}^{2+}\right)$ due to their similar chemical behaviors to $\mathrm{Hg}^{2+}[10,12-14,17-20]$. For example, Moon and coworkers [10] prepared a fluorescence sensor based upon 8-hydroxyquinoline (Figure 1a) as a $\mathrm{Hg}^{2+}$ fluorescence sensor with the detection limit of $5 \times 10^{-6} \mathrm{M}$. However, this sensor system also displayed moderate sensitivity to $\mathrm{Cu}^{2+}$ ions. Park and co-workers [14] as well as Youn and co-workers [20] prepared $\mathrm{Hg}^{2+}$-fluorescence sensors based on cyclam moieties. However, a cyclam derivative having diametrically disubstituted pyrene fluorophores (Figure 1b) [14] exhibited chemosensing behavior toward both $\mathrm{Hg}^{2+}$ and $\mathrm{Cu}^{2+}$, with a detection limit of $1.45 \times 10^{-6} \mathrm{M}$ for $\mathrm{Hg}^{2+}$. In addition, a diametrically disubstituted bis(anthrylmethyl) derivative of 1,8-dimethylcyclam (Figure 1c) presented by Youn and co-workers [20] exhibited pronounced $\mathrm{Hg}^{2+}$ and $\mathrm{Cd}^{2+}$ selective fluorogenic behaviors and the sensor provided a detection limit of $3.8 \times 10^{-6} \mathrm{M}_{\text {for }} \mathrm{Hg}^{2+}$. Song and co-workers [17] prepared a fluorescence sensor based upon the dioxocyclam moiety. They observed that the dioxocyclam derivative bearing anthrylacetamide moieties (Figure 1d) exhibited both $\mathrm{Hg}^{2+}$ and $\mathrm{Cu}^{2+}$ sensing with a detection limit of $7.8 \times 10^{-6} \mathrm{M}$ for $\mathrm{Hg}^{2+}$. Martinez and co-workers [12] introduced a fluorescence sensor based on the azine moiety. They found that 1,4-bis(1-pyrenyl)-2,3-diaza-1,3-butadiene (Figure 1e) could be employed as a fluorescence probe for both $\mathrm{Hg}^{2+}$ and $\mathrm{Cu}^{2+}$ with a detection limit of $3.4 \times 10^{-6} \mathrm{M}$ for $\mathrm{Hg}^{2+}$. For the selective recognitions presented above, ligands with only nitrogen binding sites might not be sufficient for the discrimination of potential interfering ions such as $\mathrm{Cu}^{2+}$ and $\mathrm{Cd}^{2+}$. Consequently, they are not effective as a selective $\mathrm{Hg}^{2+}$-fluorescence sensor. Figure 1 shows the chemical structures of some of the mentioned mercury sensors.

In this study, the design concept for the sensor is based on the fundamental requirements for the selective host-guest interactions in supramolecular chemistry. The major motivation of our work is the design and synthesis of mercury sensors with high sensitivity and selectivity but with a significantly reduced synthetic effort. We have focused on utilizing the new ligand, 2-[4-(2-aminoethylthio) butylthio]ethanamine (3), as an acyclic host which offers a highly flexible ligand system with appropriately located donor atoms that can self assemble around the guest molecule due to the favorable electrostatic interactions. We have chosen dansyl as a fluorophore for the construction of the chemosensor due to its strong fluorescence, relatively long emission wavelength in the visible region and structural flexibility for derivatization [9,21-23]. 
Figure 1. Chemical structures of some mercury sensors.

1a)

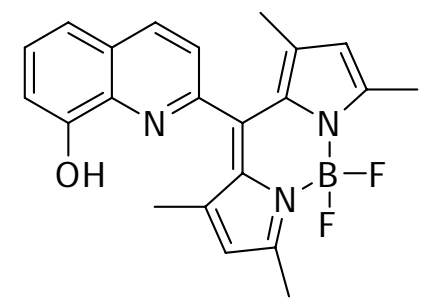

1c)

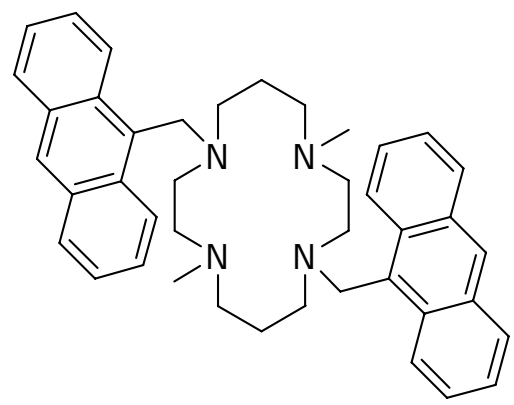

1e)

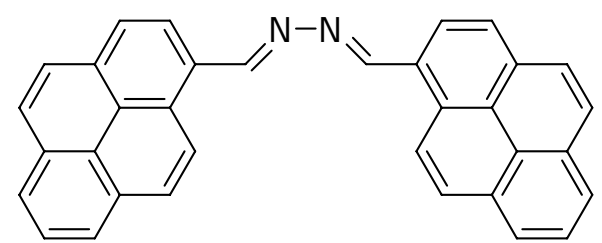

1b)<smiles></smiles>

1d)<smiles>O=C(CC(=O)Nc1ccc2cc3ccccc3cc2c1)NCCN1CCCN(CC(=O)Nc2ccc3cc4ccccc4cc3c2)CC(=O)N1</smiles>

Herein, we wish to report that the strong fluorescence of the dansyl moieties attached to 2-[4-(2aminoethylthio)butylthio]ethanamine in the novel compound $\mathbf{4}$ is quenched considerably and in a selective manner upon complexation with $\mathrm{Hg}^{2+}$. The designed compound exhibits a high $\mathrm{Hg}^{2+}$ selectivity in comparison with foreign ions $\left(\mathrm{Ag}^{+}, \mathrm{Ba}^{2+}, \mathrm{Ca}^{2+}, \mathrm{Cd}^{2+}, \mathrm{Co}^{2+}, \mathrm{Cu}^{2+}, \mathrm{Fe}^{2+}, \mathrm{Fe}^{3+}, \mathrm{Mn}^{2+}, \mathrm{Na}^{+}\right.$, $\mathrm{Ni}^{2+}, \mathrm{Pb}^{2+}$ and $\left.\mathrm{Zn}^{2+}\right)$ in acetonitrile:water solutions. Compound $\mathbf{4}$ offers sufficiently low detection limits for the determination of sub-micromolar concentrations hazardous $\mathrm{Hg}^{2+}$ ions found in environmental and biological samples such as edible fish [24].

\section{Results and Discussion}

Fluoroionophore 4 was prepared using a conventional two-step synthesis as outlined in Scheme 1. 2-[4-(2-aminoethylthio)butylthio]ethanamine (3) was prepared by alkylation of cysteamine hydrochloride (1) with 1,4-dibromobutane (2). Then compound 4 was obtained by reaction of 3 with 5-(dimethylamino)naphthalene-1-sulfonyl chloride. Compound $\mathbf{4}$ is a podant, acyclic host with pendant binding sites [25], containing two sulfur atoms and two nitrogen atoms which are covalently bound to two dansyl subunits. We expect that the selective binding will take place through electrostatic interactions between the sulfur and nitrogen atoms of the ligand and $\mathrm{Hg}^{2+}$, as these interactions are well known [10-18]. 
Scheme 1. Synthesis of 4.

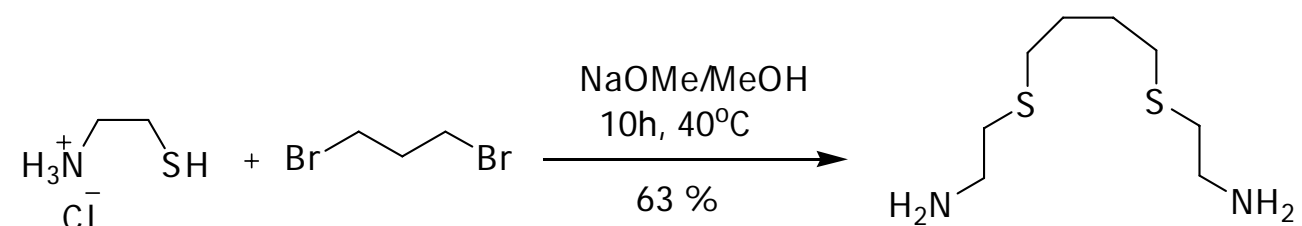

1

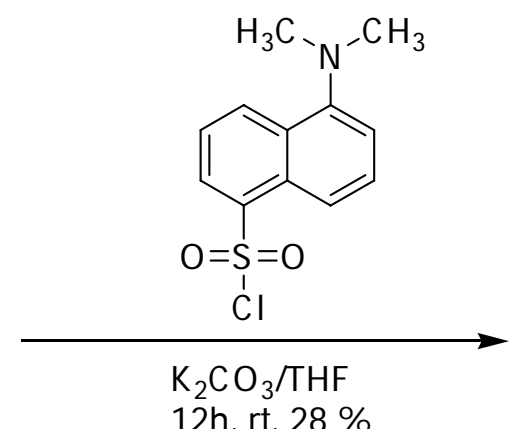

2

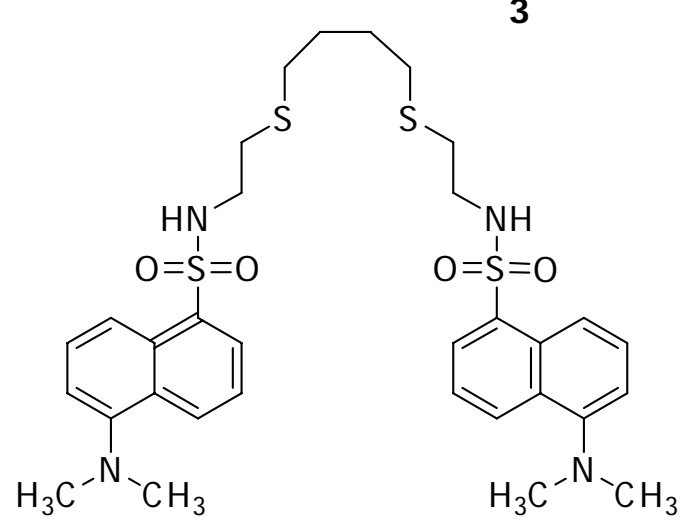

4

\subsection{Molecular modeling studies}

An attempt to theoretically estimate the binding mode diversity on the molecular recognition seen in the prominent complexation of $\mathbf{4}$ and $\mathrm{Hg}^{2+}$ is described. The helical structure of compound $\mathbf{4}$ was initially obtained from semi-empirical method using AM1 in the gas phase. Then this structure was subjected to conformation analysis by varying the possible 17 torsions and the lowest energy conformation was obtained in Figure 2a with the torsions T1: C1-C2-S14-N44, T2: C17-C18-S30N33, T3: S41-C40-C39-C38 of 122.9, 150.0, and -64.8, respectively. The absorptions of three $\mathrm{Hg}^{2+}$ loading structures were further investigated on the lowest conformation as illustrated in Figure $2 \mathrm{~b}$. The dynamics simulation was performed to obtain the possible complexes between the host and guest molecules in acetonitrile-water (95:5) using implicit distance-dependent dielectrics of 38.43 with CHARMm force field. The lowest complexation energy conformation was selected for optimization using density functional theory of local functional PWC [26] with implicit distance-dependent dielectrics of 38.43. The final structure obtained for compound $4-3 \mathrm{Hg}^{2+}$ complex is shown in Figure 2c. Each of the $\mathrm{Hg}^{2+}$ ions was located at the helical loops and coordinated with $\mathrm{S}, \mathrm{O}, \mathrm{N}$, and aromatic moieties with the favorable electrostatic interactions. The binding energy can be estimated from the difference between the energy of the complex and the sum of individual 4 and $3 \mathrm{Hg}^{2+}$ energies. The low complexation energy of $-128.621 \mathrm{kcal} / \mathrm{mol}$ showed the stability of this complex.

The molecular modeling results (Figure 2c) indicated that ions-recognition of the sensor originated from a self assembly process of compound 4 and $3 \mathrm{Hg}^{2+}$ from the favorable electrostatic interactions of $\mathrm{Hg}^{2+}$ coordinated with $\mathrm{S}, \mathrm{O}$ and $\mathrm{N}$ atoms as well as aromatic moieties (ion-dipole interaction with the middle $\mathrm{Hg}^{2+}$ and cation- $\pi$ interaction with the other two $\mathrm{Hg}^{2+}$ ions) to form a helical wrapping structure. 
Figure 2. a) The lowest optimized structure from conformational search b) the host (compound 4) - guest $\left(3 \mathrm{Hg}^{2+}\right)$ structure from MDs in acetonitrile:water (95:5) using implicit distance-dependent dielectrics of $38.43 \mathrm{c}$ ) the lowest optimized host - guest structure from MDs and optimized with local density approximation (LDA) of local functional PWC with implicit distance-dependent dielectrics of 38.43. The distances in $\AA$ between host and guest were labeled.
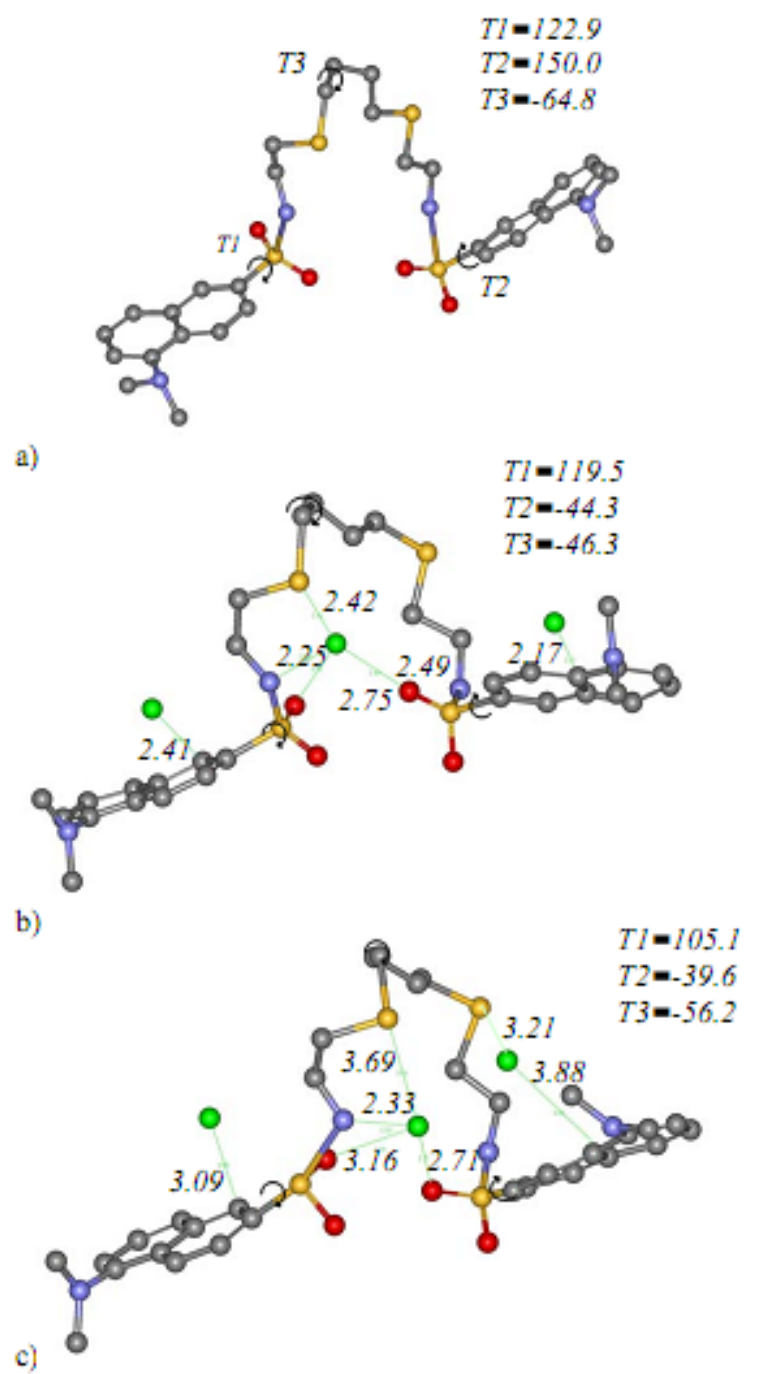

\subsection{Sensitivity studies}

In this study, the effects of water on the fluorescence emission of $\mathbf{4}$ in the absence and presence of $\mathrm{Hg}^{2+}$ were systematically investigated in acetonitrile solutions in order to optimize the conditions for practical applications in environmental and biological samples.

The effect of water content on the fluorescence behavior of $\mathbf{4}$ in acetonitrile solutions is shown in Figure 3. The fluorescence emission of 4 was found to be strongly dependent on the presence of water in the aqueous acetonitrile solutions. This result illustrated that when the concentration of water increased, the fluorescence emission intensity of 4 decreased progressively. In the low water concentration range, a similar decrease in the response of 4 in the presence of 20 equivalents of $\mathrm{Hg}^{2+}$ was observed, but with much larger changes compared to the high water concentration region. Based 
on this observation, we focused on the fluorescence behaviors of $\mathbf{4}$ in response to the various metal ions in 80:20 acetonitrile:water solution.

Figure 3. Fluorescence intensity changes of $4(0.5 \mu \mathrm{M})$ as a function of water content in aqueous acetonitrile solution at $515 \mathrm{~nm}$ in the absence and presence of $\mathrm{Hg}^{2+}$ (20 equiv), $\lambda_{\text {ex }}$ $338 \mathrm{~nm}$.

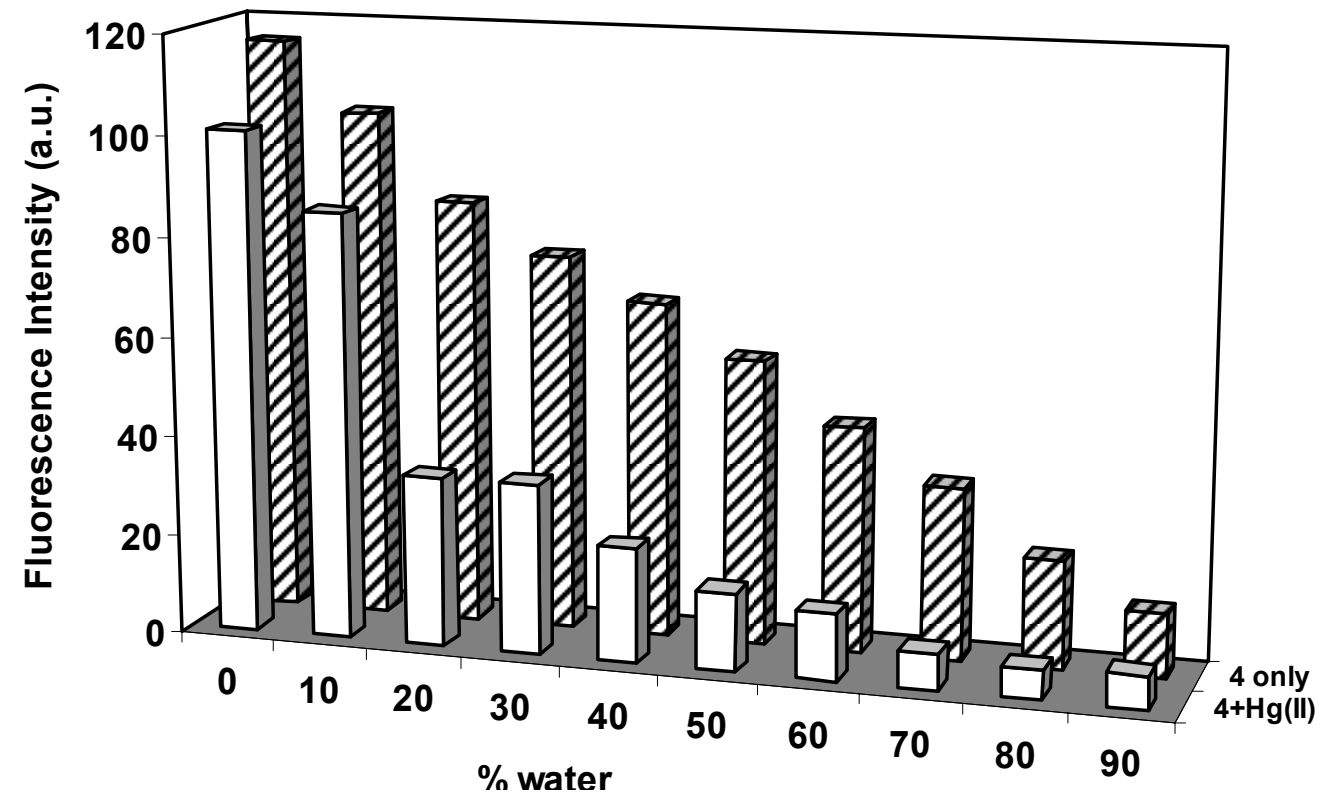

To elucidate the quantitative binding affinity of $\mathbf{4}$, fluorescence titrations of $\mathbf{4}$ with $\mathrm{Hg}^{2+}$ were carried out. Figure 4 shows the fluorescence spectra obtained from 4 in the absence and presence of $\mathrm{Hg}^{2+}$ in 80:20 acetonitrile-water.

Figure 4. Fluorescence emission spectra $\left(\lambda_{\text {ex }} 338 \mathrm{~nm}\right)$ of $4(0.25 \mu \mathrm{M})$ in 80:20 $\mathrm{CH}_{3} \mathrm{CN}: \mathrm{H}_{2} \mathrm{O}$ as function of $\left[\mathrm{Hg}^{2+}\right]$. a: $0 \mathrm{M}, \mathrm{b}: 0.27 \mu \mathrm{M}$, c: $0.33 \mu \mathrm{M}$, d: $0.40 \mu \mathrm{M}$, e: 0.47 $\mu \mathrm{M}, \mathrm{f}: 0.53 \mu \mathrm{M}, \mathrm{g}: 0.60 \mu \mathrm{M}, \mathrm{h}: 0.67 \mu \mathrm{M}$, i: $1.00 \mu \mathrm{M}$.

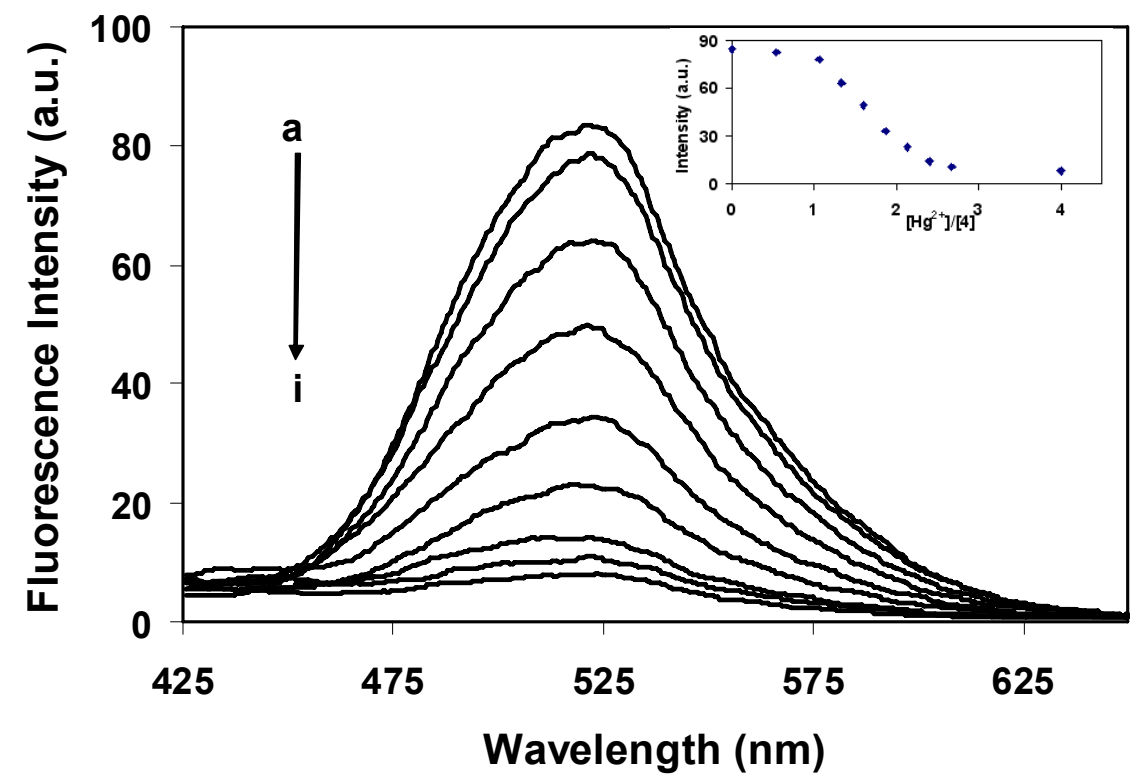


When an ion-complexation was operative, an ON-OFF switching occurred as indicated by the fluorescence emission behavior. In the absence of $\mathrm{Hg}^{2+}$ ions, the fluorescence response was at a maximum and the response decreased as the mercury concentration was increased. When the added mercury acetate attained a concentration approximately more than three times higher than that of $\mathbf{4}$, more than $90 \%$ quenching of initial fluorescence of 4 was observed and the fluorescence response reached a minimum point. The inset of Figure 4 shows the break around 3-4 equiv of $\mathrm{Hg}^{2+}$ which could suggest a 1:3 or 1:4 stoichiometry for the $4-\mathrm{Hg}^{2+}$ complex system [18]. Further studies by molecular modeling using Material Studio 4.3 suggested that the complex formation having the 1:3 (host 4: guest $\left.\mathrm{Hg}^{2+}\right)$ stoichiometry was appropriate and provided the most stable complexation $(-128.621 \mathrm{kcal} / \mathrm{mol})$ while the complex of 1:4 (host 4: guest $\mathrm{Hg}^{2+}$ ) could not be formed. The association constant, $K_{\text {assoc }}$, was determined by nonlinear curve fitting of the signal changes in the fluorescence titration results $[10,14,27-28]$. It was found to be $1.15 \times 10^{19} \mathrm{M}^{-3}$ and the $1: 3$ complex formation of $4-\mathrm{Hg}^{2+}$ was suggested.

A similar quenching behavior upon $\mathrm{Hg}^{2+}$ binding was previously observed in many mercury fluorescence sensors [10,16-18,20], and a mechanism such as the photo-induced electron transfer (PET) process was suggested $[9,20]$. For this system, the fluorescence quantum yield $\left(\phi_{\mathrm{f}}\right)$ of 4 in acetonitrile was found to be 0.55 , using quinine sulfate as a reference [29]. However, the $\phi_{\mathrm{f}}$ of the $1: 3$ complex formation of $4-\mathrm{Hg}^{2+}$ was found to be 0.54 . An insignificant change of the quantum yield indicated that the quenching mechanism upon $\mathrm{Hg}^{2+}$ binding to 4 did not occur via the PET process for this system. The effective fluorescence quenching of $\mathbf{4}$ might be due to the inherent quenching nature of $\mathrm{Hg}^{2+}$ ions as suggested by Chang and co-workers [15,17-18].

The data collected in Figure 4 provided a good linear correlation between the emission response and $\mathrm{Hg}^{2+}$ concentration over a range of 53-120 ppb, which is sufficient for the detection of submicromolar concentrations of $\mathrm{Hg}^{2+}$ found in many biological systems such as edible fish [24]. The detection limit of $\mathbf{4}$ as a fluorescent sensor for the analysis of $\mathrm{Hg}^{2+}$ was determined from the plot of the fluorescence intensity as a function of the $\mathrm{Hg}^{2+}$ concentrations [30] and was found to be approximately $50 \mathrm{ppb}$.

\subsection{Selectivity studies}

Selectivity studies of $\mathbf{4}$ were performed in 80:20 acetonitrile-water solutions by recording the fluorescence spectra of the solutions of 4 after the addition of each representative metal ions. Figure 5 shows the dependence of the fluorescence intensity of $\mathbf{4}$ as a function of cation concentrations for $\mathrm{Hg}^{2+}$, transition-metal, heavy metal, alkali earth and alkali ions including $\mathrm{Ag}^{+}, \mathrm{Ba}^{2+}, \mathrm{Ca}^{2+}, \mathrm{Cd}^{2+}, \mathrm{Co}^{2+}$, $\mathrm{Cu}^{2+}, \mathrm{Fe}^{2+}, \mathrm{Fe}^{3+}, \mathrm{Mn}^{2+}, \mathrm{Na}^{+}, \mathrm{Ni}^{2+}, \mathrm{Pb}^{2+}$ and $\mathrm{Zn}^{2+}$. Herein, the sensitivity studies of $\mathbf{4}$ were performed in 80:20 acetonitrile:water solution by a similar method to the Separate Solution Method (SSM) used in ion-selective electrode applications [31]. This method involves the measurement of a series of separate solutions, each containing only a salt of the determined ion [31]. 
Figure 5. a) Fluorescence spectra $\left(\lambda_{\mathrm{ex}}=338 \mathrm{~nm}\right)$ of $4(0.25 \mu \mathrm{M})$ with addition of acetate salts of $\mathrm{Hg}^{2+}, \mathrm{Ag}^{+}, \mathrm{Ba}^{2+}, \mathrm{Ca}^{2+}, \mathrm{Cd}^{2+}, \mathrm{Co}^{2+}, \mathrm{Cu}^{2+}, \mathrm{Fe}^{2+}, \mathrm{Fe}^{3+}, \mathrm{Mn}^{2+}, \mathrm{Na}^{+}, \mathrm{Ni}^{2+}, \mathrm{Pb}^{2+}$ and $\mathrm{Zn}^{2+}$ $(1.00 \mu \mathrm{M})$ b) Normalized emission intensity $(515 \mathrm{~nm})$ of $4(0.25 \mu \mathrm{M})$ versus the concentration of various metal ions in $80: 20 \mathrm{CH}_{3} \mathrm{CN}: \mathrm{H}_{2} \mathrm{O}$.

a)

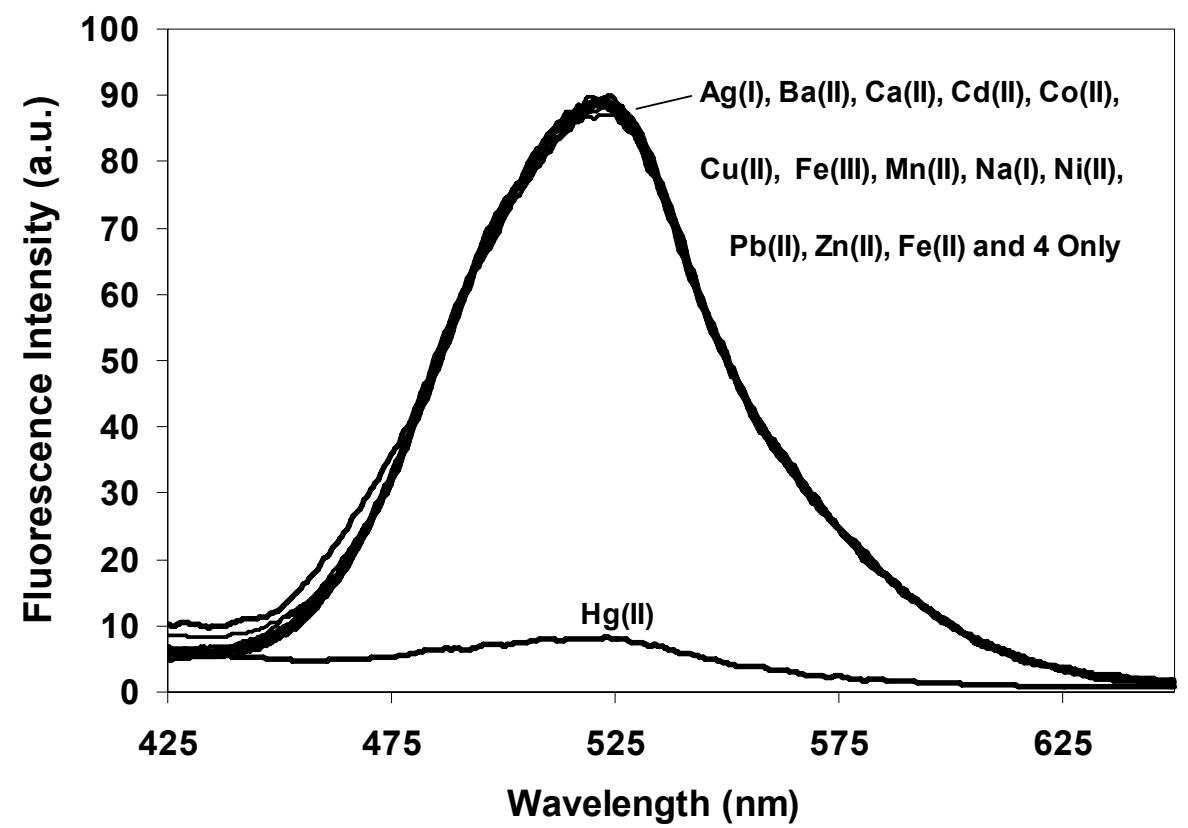

b)

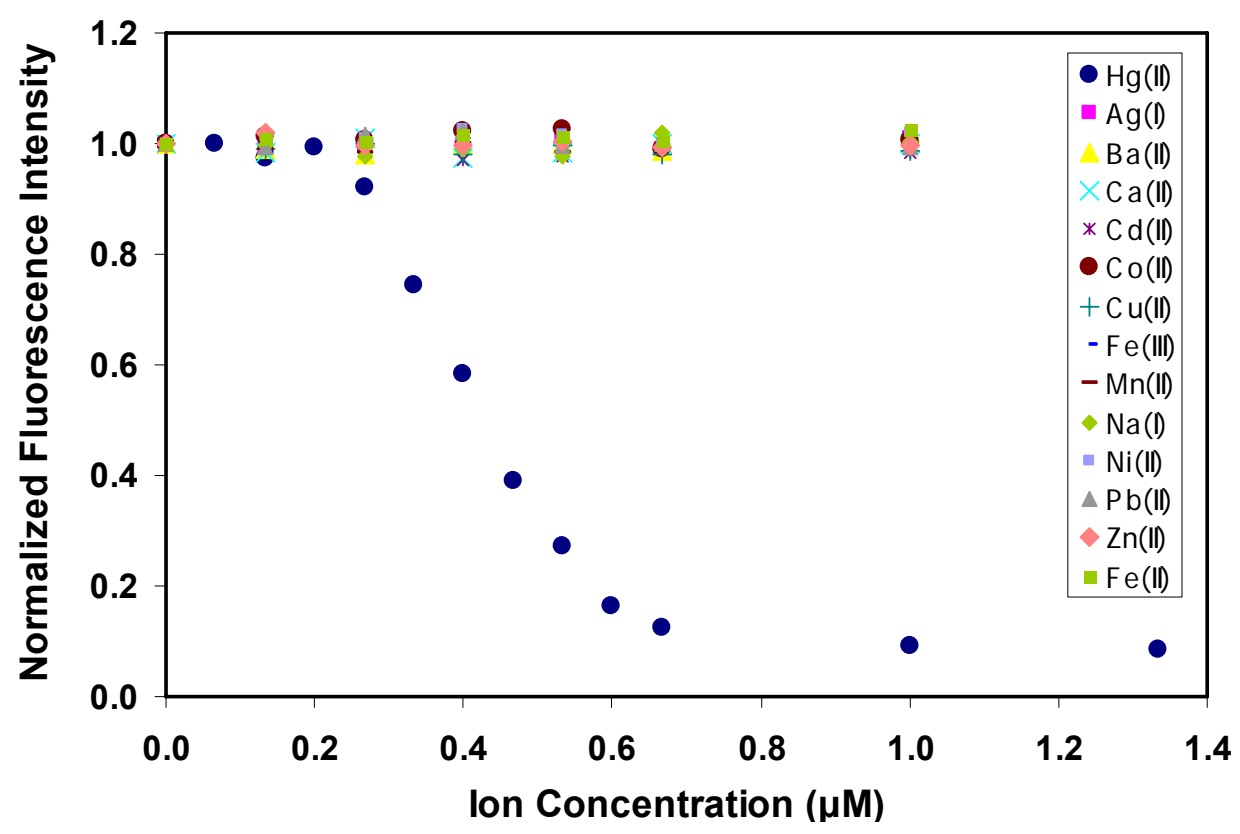

The selectivity studies clearly demonstrated the high selectivity of $\mathbf{4}$ to $\mathrm{Hg}^{2+}$ in comparison with the other cations. The results showed that the fluorescence intensity of $\mathbf{4}$ decreased as a function of added $\mathrm{Hg}^{2+}$ until the minimum point was reached, beyond which it was constant up to the maximum concentration tested. In contrast, the fluorescence response of $\mathbf{4}$ promoted a small change after the addition of other foreign ions under identical conditions. It should be noted here that $\mathbf{4}$ showed high selectivity for $\mathrm{Hg}^{2+}$ over $\mathrm{Ag}^{+}, \mathrm{Cu}^{2+}$ and $\mathrm{Cd}^{2+}$ which are potential competitors [12-14,17-20]. 
We have therefore demonstrated that our new ligand, 2-[4-(2-aminoethylthio)butylthio]ethanamine, meets the fundamental requirements for the selective host-guest interactions in supramolecular chemistry for chelating $\mathrm{Hg}^{2+}$. The sensor fabricated from the ligand with appropriately located donor atoms $(\mathrm{S}, \mathrm{N}, \mathrm{O})$ can provide selective self assembly around $\mathrm{Hg}^{2+}$ due to the favorable electrostatic interactions (ion-dipole interactions). Due to the advantages of high selectivity and synthetic simplicity, 2-[4-(2-aminoethylthio)butylthio]ethanamine could therefore be utilized as a potential mercury ligand for future applications.

\section{Experimental}

\subsection{General}

Barium acetate was purchased from Sigma-Aldrich. Cadmium acetate was purchased from Merck and cobalt acetate was purchased from Prolabo. All other reagents and solvents for synthesis were purchased from Fluka Chemical Corporation and were used as received, unless stated otherwise. Aqueous solutions were freshly prepared using high-purity Millipore deionized water $(18 \mathrm{M} \Omega . \mathrm{cm})$.

NMR spectra were obtained with a Bruker Avance spectrometer operating at $300 \mathrm{MHz}$ for proton and $75 \mathrm{MHz}$ for ${ }^{13} \mathrm{C}$. All NMR spectra were obtained on $\mathrm{CDCl}_{3}$ solutions. Mass spectra were performed by a ThermoElectron LCQ-DECA-XP, electrospray ionization ion trap mass spectrometer.

Fluorescence measurements: Fluorescence emission and excitation spectra of $\mathbf{4}$ were obtained with a Perkin Elmer Luminescence spectrometer LB50 with the use of 80:20 acetonitrile-water as solvent, with an excitation wavelength $338 \mathrm{~nm}$. Typical solutions were made with fluoroionophore $4(0.25$ $\mu \mathrm{M})$. Metal ions were added as the acetate salts. Fluorescence was measured as a function of metal ions concentration. For selectivity studies, fluorescence intensity was determined at a fixed wavelength $(515 \mathrm{~nm})$.

\subsection{Synthesis of 2-[4-(2-aminoethylthio)butylthio]ethanamine (3)}

In a round bottom flask, sodium methoxide $(0.68 \mathrm{~g}, 12.00 \mathrm{mmol})$ was dissolved in dry methanol (3 $\mathrm{mL})$. Cysteamine hydrochloride $(1.14 \mathrm{~g}, 10.03 \mathrm{mmol})$ was added to the solution. The solution was then stirred for $30 \mathrm{~min}$ where upon 1,4-dibromobutane $(0.5 \mathrm{~mL}, 4.14 \mathrm{mmol})$ was added. This solution was then stirred for an additional $10 \mathrm{~h}$ at $40{ }^{\circ} \mathrm{C}$ under an argon atmosphere. The solvent was subsequently removed by a rotary evaporator. Aqueous sodium hydroxide solution $(30 \% \mathrm{w} / \mathrm{v}, 15 \mathrm{~mL})$ was added to the residue and the resulting solution was slowly stirred overnight. Then, the solution was extracted three times each with $20 \mathrm{~mL}$ of dichloromethane. The dichloromethane phase was collected and washed once with $60 \mathrm{~mL}$ of distilled water and then dried over anhydrous $\mathrm{Na}_{2} \mathrm{SO}_{4}$. The dichloromethane was removed under vacuum to give $0.54 \mathrm{~g}$ of the product as yellow oil (63\% yield). The product was used without further purification. ${ }^{1} \mathrm{H}-\mathrm{NMR}\left(\mathrm{CDCl}_{3}\right) \delta 1.58(\mathrm{~s}, 4 \mathrm{H}), 1.63-1.75(\mathrm{~m}$, $4 \mathrm{H}), 2.43-2.57(\mathrm{~m}, 4 \mathrm{H}), 2.57-2.71(\mathrm{~m}, 4 \mathrm{H}), 2.81-2.91(\mathrm{~m}, 4 \mathrm{H}) ;{ }^{13} \mathrm{C}-\mathrm{NMR}\left(\mathrm{CDCl}_{3}\right) \delta 32.5\left(2 \mathrm{CH}_{2}\right), 35.2$ $\left(2 \mathrm{CH}_{2}\right), 39.2\left(2 \mathrm{CH}_{2}\right), 44.4\left(2 \mathrm{CH}_{2}\right)$; HRMS calcd for $\mathrm{C}_{8} \mathrm{H}_{21} \mathrm{~N}_{2} \mathrm{~S}_{2}(\mathrm{M}+\mathrm{H})^{+} 209.1146 \mathrm{~m} / \mathrm{z}$, found $209.1073 \mathrm{~m} / \mathrm{z}$. 


\subsection{Synthesis of compound 4}

In a round bottom flask, 2-[4-(2-aminoethylthio)butylthio]ethanamine (3) $0.10 \mathrm{~g}, 0.48 \mathrm{mmol})$ and $\mathrm{K}_{2} \mathrm{CO}_{3}(0.26 \mathrm{~g}, 1.92 \mathrm{mmol})$ were stirred in dry tetrahydrofuran $(7 \mathrm{~mL})$ for $30 \mathrm{~min}$ under an argon atmosphere. 5-(Dimethylamino)naphthalene-1-sulfonyl chloride $(0.32 \mathrm{~g}, 1.20 \mathrm{mmol})$ was added and the reaction mixture was stirred for $12 \mathrm{~h}$ at room temperature. The potassium carbonate was filtered off and carefully washed with dichloromethane. The solvent was removed under vacuum. The crude product was purified by preparative thin layer chromatography $\left(\mathrm{CH}_{2} \mathrm{Cl}_{2}: \mathrm{MeOH}\right.$ 99:1 eluent) to afford $92.2 \mathrm{mg}$ of a yellow oil in $28 \%$ yield. $R_{\mathrm{f}}=0.29\left(\mathrm{CH}_{2} \mathrm{Cl}_{2}: \mathrm{MeOH} 99: 1\right) ;{ }^{1} \mathrm{H}-\mathrm{NMR}\left(\mathrm{CDCl}_{3}\right) \delta 1.31-1.41$ (m, 4H), $1.61(\mathrm{~s}, 4 \mathrm{H}), 2.06-2.24(\mathrm{~m}, 4 \mathrm{H}), 2.49(\mathrm{t}, J=6.3 \mathrm{~Hz}, 4 \mathrm{H}), 2.89$ (s, 12H), 3.02 (q, J=6.3 Hz, $4 \mathrm{H}), \quad 7.18(\mathrm{~d}, \quad J=7.5 \mathrm{~Hz}, 2 \mathrm{H}), \quad 7.47-7.62(\mathrm{~m}, 4 \mathrm{H}), 8.20-8.32(\mathrm{~m}, 4 \mathrm{H}), 8.54 \quad(\mathrm{~d}$, $J=8.4 \mathrm{~Hz}, 2 \mathrm{H}) ;{ }^{13} \mathrm{C}-\mathrm{NMR}\left(\mathrm{CDCl}_{3}\right) \delta 28.0\left(2 \mathrm{CH}_{2}\right), 30.6\left(2 \mathrm{CH}_{2}\right), 31.7\left(2 \mathrm{CH}_{2}\right), 41.7\left(2 \mathrm{CH}_{2}\right), 45.4$ $\left(4 \mathrm{CH}_{3}\right), 115.3(2 \mathrm{C}), 118.6(2 \mathrm{C}), 123.2$ (2C), 128.5 (2C), 129.7 (2C), 130.6 (2C), $129.6(2 \mathrm{C}), 129.8$ (2C), 134.5 (2C), 152.0 (2C); HRMS calcd for $\mathrm{C}_{32} \mathrm{H}_{43} \mathrm{~N}_{4} \mathrm{O}_{4} \mathrm{~S}_{4}(\mathrm{M}+\mathrm{H})^{+} 675.2167 \mathrm{~m} / \mathrm{z}$, found 675.2000 $\mathrm{m} / \mathrm{z}$.

\subsection{Computational modeling of complex structure with mercury}

Two end chains [- $\mathrm{SO}_{2} \mathrm{C}_{10} \mathrm{H}_{6}\left(\mathrm{CH}_{3}\right)_{2}$ ] of compound 4 were obtained from the X-ray crystal structure (PDB ID: 1BDA) where the straight chain in the middle was built using Material Studio 4.3. Then, this initial structure was optimized using AM1 method with RHF in the gas phase. The optimized structure was submitted to the conformers module within the same program software package to generate conformers of the molecule using Boltzman jump method with the number of perturbation per jump $=50$ at $5000 \mathrm{~K}[32-34]$. All possible 17 torsion angles of compound 4 were rotated with $10 \AA$ torsion angle step. The lowest energy conformer was initially obtained as Figure 1a). Host-guest calculation was performed with three $\mathrm{Hg}^{2+}$ ions loading (according to experimental results) where each $\mathrm{Hg}^{2+}$ ion was positioned about the middle of the three helical loops. These systems were minimized and dynamics simulation in acetonitrile:water (95:5) was performed using implicit distance-dependent dielectrics of 38.43 with CHARMm force field. The formal charge for $\mathrm{Hg}^{2+}$ was assigned. Molecular dynamics (MDs) was obtained at the constant temperature at $300 \mathrm{~K} 100$ ps with constraint force of $0.01 \mathrm{kcal} / \mathrm{mol} / \AA^{2}$ under NVT ensemble. Time step of $1 \mathrm{fs}$ was used in all simulations. The MDs structure was analyzed in detail in Discovery Studio Version 1.7 program package. The lowest complexation energy of the host-guest structure from the dynamics simulation was further optimized with more accurate calculation method using density functional theory with local density approximation (LDA) of local functional PWC [26] with implicit distance-dependent dielectrics of 38.43 and the final structure of complexation of $\mathbf{4}$ and $3 \mathrm{Hg}^{2+}$ ions complex was obtained.

\section{Conclusions}

In summary, we have discovered a new mercury fluoroionophore that exhibited high selectivity for $\mathrm{Hg}^{2+}$ over a wide range of foreign ions, but with a significantly reduced synthetic effort. Compound 4 consists of two dansyl fluorophores covalently bound to 2-[4-(2-aminoethylthio)butylthio] ethanamine. The sensor was prepared by a conventional two-step synthesis. The $\mathrm{Hg}^{2+}$-selective fluorescence 
quenching of 4 was observed in aqueous acetonitrile solutions with the detection limit of $2.49 \times 10^{-7} \mathrm{M}$ or $50 \mathrm{ppb}$. The molecular design presented here could serve as an alternative mercury fluorometric sensor due to the advantage of sensitivity, selectivity and synthetic simplicity. We have therefore developed a highly selective and sensitive fluoroionophore for $\mathrm{Hg}^{2+}$ detection and the ready synthetic access to the dansyl-based fluoroionophore could make it an attractive mercury sensor for many potential applications.

\section{Acknowledgements}

This work was supported by Grant MRG5180206 from the Thailand Research Fund, the Center for Innovation in Chemistry (PERCH-CIC), and Commission on Higher Education, Ministry of Education of Thailand. The authors would like to express grateful acknowledgement to Computational Nanoscience Consortium (CNC), Nanotechnology (NANOTEC), Thailand for the access to Discovery Studio Version 1.7 program package.

\section{References and Notes}

1. Tchounwou, P.B.; Ayensu, W.K.; Ninashvili, N.; Sutton, D. Environmental exposure to mercury and its toxicopathologic implications for public health. Environ. Toxicol. 2003, 18, 149-175.

2. Singh, A.K.; Bhattacharjee, G.; Singh, R. Mercury(II)-selective membrane electrode using tetrathia-diazacyclotetradeca-2,9-diene as neutral carrier. Sens. Actuat. B 2004, 99, 36-41.

3. Guo, X.; Qian, X.; Jia, L. A highly selective and sensitive fluorescent chemosensor for $\mathrm{Hg}^{2+}$ in neutral buffer aqueous solution. J. Am. Chem. Soc. 2004, 126, 2272-2273.

4. Talanova, G.G.; Elkarim, N.S.A.; Talanov, V.S.; Bartsch, R.A. A calixarene-based fluorogenic reagent for selective mercury (II) recognition. Anal. Chem. 1999, 71, 3106-3109.

5. Shiraishi, Y.; Sumiya, S.; Kohno, Y.; Hirai, T.A. Rhodamine-cyclen conjugate as a highly sensitive and selective fluorescent chemosensor for $\mathrm{Hg}(\mathrm{II})$. J. Org. Chem. 2008, 73, 8571-8574.

6. Soh, J.H.; Swamy, K.M.K.; Kim, S.K.; Kim, S.H.; Lee, S.H.; Yoon, J. Rhodamine urea derivatives as fluorescent chemosensors for $\mathrm{Hg}^{2+}$. Tetrahedron Lett. 2007, 48, 5966-5969.

7. Wang, F.; Peng, R.; Sha, Y. Selective Dendritic Fluorescent Sensors for Zn(II). Molecules 2008, 13, 922-930.

8. Peng, R.; Wang, F. Synthesis of 5-Dialkyl(aryl)aminomethyl-8-hydroxyquinoline dansylates as selective fluorescent sensors for $\mathrm{Fe}^{3+}$. Molecules 2007, 12, 1191-1201.

9. Metivier, R.; Leray, I.; Valeur, B. Lead and mercury sensing by calixarene-based fluoroionophores bearing two or four dansyl fluorophores. Chem. Eur. J. 2004, 10, 4480-4490.

10. Moon, S.Y.; Cha, N.R.; Kim, Y.H.; Chang, S.K. New $\mathrm{Hg}^{2+}$-selective chromo- and fluoroionophore based upon 8-hydroxyquinoline. J. Org. Chem. 2004, 69, 181-183.

11. Zhang, H.; Han, L.F.; Zachariasse, K.A.; Jiang, Y.B. 8-Hydroxyquinoline benzoates as highly sensitive fluorescent chemosensors for transition metal ions. Org. Lett. 2005, 7, 4217-4220.

12. Martinez, R.; Espinosa, A.; Tarraga, A.; Molina, P. New $\mathrm{Hg}^{2+}$ and $\mathrm{Cu}^{2+}$ selective chromo- and fluoroionophore based on a bichromophoric azine. Org. Lett. 2005, 7, 5869-5872.

13. Kim, S.H.; Kim, J.S.; Park, S.M.; Chang, S.K. $\mathrm{Hg}^{2+}$-selective OFF-ON and $\mathrm{Cu}^{2+}$-selective ONOFF type fluoroionophore based upon cyclam. Org. Lett. 2006, 8, 371-374. 
14. Park, S.M.; Kim, M.H.; Choe, J.I.; No, K.T.; Chang, S.K. Cyclams bearing diametrically disubstituted pyrenes as $\mathrm{Cu}^{2+}$ - and $\mathrm{Hg}^{2+}$-selective fluoroionophores. J. Org. Chem. 2007, 72, 3550-3553.

15. Moon, S.Y.; Youn, N.J.; Park, S.M.; Chang, S.K. Diametrically disubstituted cyclam derivative having $\mathrm{Hg}^{2+}$ - selective fluoroionophoric behaviors. J. Org. Chem. 2005, 70, 2394-2397.

16. Kim, J.H.; Hwang, A.R.; Chang, S.K. $\mathrm{Hg}^{2+}$-selective fluoroionophore of p-tert-butylcalix[4]arene -diaza-crown ether having pyrenylacetamide subunits. Tetrahedron Lett. 2004, 45, 7557-7561.

17. Song, K.C.; Kim, M.H.; Kim, H.J.; Chang, S.K. $\mathrm{Hg}^{2+}$ - and $\mathrm{Cu}^{2+}$-selective fluoroionophoric behaviors of a dioxocyclam derivative bearing anthrylacetamide moieties. Tetrahedron Lett. 2007, 48, 7464-7468.

18. Kim, S.H.; Song, K.C.; Ahn, S.; Kang, Y.S.; Chang, S.K. $\mathrm{Hg}^{2+}$-selective fluoroionophoric behavior of pyrene appended diazatetrathia-crown ether. Tetrahedron Lett. 2006, 47, 497-500.

19. Rurack, K.; Kollmannsberger, M.; Resch-Genger, U.; Daub, J. A selective and sensitive fluoroionophore for $\mathrm{Hg}(\mathrm{II}), \mathrm{Ag}(\mathrm{I})$, and $\mathrm{Cu}(\mathrm{II})$ with virtually decoupled fluorophore and receptor units. J. Am. Chem. Soc. 2000, 122, 968-969.

20. Youn, N.J.; Chang, S.K. Dimethylcyclam based fluoroionophore having $\mathrm{Hg}^{2+}-$ and $\mathrm{Cd}^{2+}$ selective signalin behaviors. Tetrahedron Lett. 2005, 46, 125-129.

21. Lim, M.H.; Lippard, S.J. Fluorescent nitric oxide detection by copper complexes bearing anthracenyl and dansyl fluorophore ligands. Inorg. Chem. 2006, 45, 8980-8989.

22. Chen, C.F.; Chen, Q.Y. A tetra-sulfonamide derivative bearing two dansyl groups designed as a new fluoride selective fluorescent chemosensor. Tetrahedron Lett. 2004, 45, 3957-3960.

23. Sulowska, H.; Wiczk, W.; Mlodzianowski, J.; Przyborowska, M.; Ossowski, T. Synthesis and fluorescence behaviour of crown and azacrown ethers carrying the dansyl fluorophore as a pendant in acetonitrile solution. J. Photochem. Photobiol. A 2002, 150, 249-255.

24. Yoon, S.; Albers, A.E.; Wong, A.P.; Chang, C.J. Screening mercury levels in fish with a selective fluorescent chemosensor. J. Am. Chem. Soc. 2005, 127, 16030-16031.

25. Steed, J.W.; Atwood, J.L. Supramolecular Chemistry; John Wiley \& Sons, Inc.: New York, NY, USA, 2000; pp. 92-94.

26. Perdew, J.P.; Wang, Y. Accurate and simple analytic representation of the electron-gas correlation energy. Phys. Rev. B 1992, 45, 13244-13249

27. Valeur, B.; Pouget, J.; Bourson, J.; Kaschke, M.; Ernsting, N. P. Tuning of photoinduced energy transfer in a bichromophoric coumarin supermolecule by cation binding. J. Phys. Chem. 1992, 96, 6545-6549.

28. Bourson, J.; Pouget, J.; Valeur, B. Ion-responsive fluorescent compounds. 4. Effect of cation binding on the photophysical properties of a coumarin linked to monoaza- and diaza-crown ethers. J. Phys. Chem. 1993, 97, 4552-4557.

29. Crosby, G.A.; Demas, J.N. Measurement of photoluminescence quantum yields. J. Phys. Chem. 1971, 75, 991-1024.

30. Shortreed, M.; Kopelman, R.; Kuhn, M.; Hoyland, B. Fluorescent fiber-optic calcium sensor for physiological measurements. Anal. Chem. 1996, 68, 1414-1418.

31. Bakker, E.; Buhlmann, P.; Pretsch, E. Carrier-based ion-selective electrodes and bulk optodes. 1. General characteristics. Chem. Rev. 1997, 97, 3083-3132. 
32. Cerný, V. A thermodynamical approach to the travelling salesman problem: An efficient simulation algorithm. J. Optim. Theor. Appl. 1985, 45, 41-51.

33. Kirkpatrick, S.; Gelatt, C.D.; Vecchi, M.P. Optimization by Simulated Annealing. Science 1983, 220, 671-680.

34. Metropolis, N.; Rosenbluth, A.W.; Rosenbluth, M.N.; Teller, A.H.; Teller, E. Equation of state calculations by fast computing machines. J. Chem. Phys. 1953, 21, 1087-1092.

Sample Availability: Samples of the compounds $\mathbf{3}$ and $\mathbf{4}$ are available from the authors.

(C) 2010 by the authors; licensee Molecular Diversity Preservation International, Basel, Switzerland. This article is an open-access article distributed under the terms and conditions of the Creative Commons Attribution license (http://creativecommons.org/licenses/by/3.0/). 